reports that, in one of his cases, he fastened in the wound a tube made somewhat after the pattern of a tracheotomy tube, but that it was abandoned in a day or two.

I think there can be no doubt as to the propriety of these operations, and I venture to predict that the time will soon come when it will be considered a far more criminal matter to neglect such practice when the great cavities of the body with their vital organs are involved, than to omit the evacuation of pus from superficial abseesses, which we al. ways anree should be done as soon as the presence of pus is diagnosticated. Now that we have the aspirator, that harmless but life-saving instrument, as an aid in diagnosis, there is no excuse for not doing all that should be done. Physicians have always feared the admission of air to serous surfaces, and we were taught the importance of making a valvular incision in performing the operation of paracentesis thoracis in order to avoid atmospheric contact, but it is found now that the largest percentage of success in ovariotomy is obtained where free and complete drainage is established, thus avoiding septicamia and peritonitis.

No'te. - At the present date, August 17th, the fittle patient whose case is here related is apparently in perfect health, and the respiratory murmur is clear and distinct over the whole lung. In conclusion, I will only say that the lesson taught me by this case is to recognize early the presence of pus in the thoracic cavity after pleuro-pneumonia, and then at once to evacuate it, and keep the cavity dianed and cleansed until it is evident that a healthy action is restored. The narrow escape from death in this instance demonstrated to me that many valuable lives might be saved by employing seasonably this means for their safety.

\title{
A COMPLICATED CASE OF LABOR.
}

uY J. O. MARHLE, M. D., OF WORChster.

Ar half past six A. M. of September 17, 1875, I was called to attend Mrs. K., aged thirty-four, in her fourth pregnancy, in labor about an hour. I was speedily at her side, having attended her in a very rapid labor less than two years previously. I found her walking about, with severe pains; she said that she "knew something was wrong," and that a deluge of water had just escaped from her. I had her bed prepared, and after much urging persuaded her to lie down. On making a vaginal examination I found the os filly dilated and a soft mass presenting, which $I$ at first took to be a slroulder. Making further exploration I distinctly felt a head lying to the left of the soft mass, and firmly pressed against it. A little further manipulation convinced me that I had to 
deal with a twin labor, and that the soft mass was a breech. Remembering the increased danger to the child when the first of twins is delivered by the breech, I introduced two fingers of my hand into the vagina and attempted to press back the breech, and so to allow the head to engrage; but my efforts were vain, for at the moment a violent contraction of the uterus drove the breech through into the vagina, and two more expelled the body of the child as far as the shoulders. The uterus then relaxed, and no pain recurred for several minutes. In making traction upon the body of the child I found the head as firmly held as if in a vise. There was already little pulsation in the cord, and the extremities were becoming blue. A large quantity of meconium was passed. Feeling the necessity of speedy delivery, and believing the heads to be locked together, that of one lying beside the neck of the other (as in the case described in the last edition of Cazeaux ${ }^{1}$ ), I insinuated my hand along the chest of the child up to the second presenting head, and, as the pains fortumately were now entirely suspended, succeeded in pushing it back, at the same time making strong traction with the other hand upon the body of the partially delivered child. I then succeeded in passing one of the fingers, with which I had pressed up the second head, into the mouth of the other, drew its chin close upon its chest, and, imitating nature in making rotation as far as possible, had little further difficulty in delivering the foetus. The child appeared to be dead, but by the usual means it was soon made to gasp, and then to cry lustily.

While I was occupied in its resuscitation a single powerful contraction brought the second child into the world, enveloped in the amnion, having "taken the veil" along with it. I ruptured the ammion, which contained about four ounces of fluid, and to my surprise the diminutive thing cried out sharply, though feebly. The first ehild weighed nine and three quarters pounds; it was remarkably well developed and of a healthy pink color. 'The second weighed scarcely five pounds, and was covered with the thickest coating of vernix caseosa I have ever seen; it had the most ludicrous pinched and old expression of face. Both the children were females. The placenta was common, with the two cords at about equal distances from centre and circumference; its diameter was nine and a half inches. There was no difference apparently in its sides, and one child's source of supply appeared as good as that of the other. The same chorion embraced them both, but each had its own amnion.

The circumference of the head of the larger (corresponding to the sub-occipito-bregmatic diameter) was thirteen inches; that of the smaller ten and a half. 'The motlier's pelvis is very capacious. The three patients are now perfectly well, the pygmy rapidly gaining on her larger sister.

\section{Page 865.}

